\title{
The Prefabricated Construction Project's Problems and Countermeasures of Construction Site Management
}

\author{
Sanlong Man ${ }^{1, *}$ \\ ${ }^{1}$ School of Civil Engineering, North China University of Technology, China
}

\begin{abstract}
In comparison of the traditional building system, prefabricated building can reflect the development trend of building industrialization. Prefabricated building speeds up the construction by manufactured high-quality and high-precision components in the factory; then assembling the components to the construction site. Which can meet the requirements of green building without the need of cast-inplace and assembly. However, the application of prefabricated building also has limitations: prefabricated building is still lack of perfect relevant standards and component atlas; compared with the traditional pouring building, the mechanical and seismic performance of prefabricated building is poor. In the aspect of factory manufacturing, there are some problems. For example, because the form of prefabricated components is monotonous, it is difficult to meet the diverse appearance requirements of buildings. At present, the improvement of prefabricated building mainly focuses on the production and construction technology of components, but it lacks the improvement of the project management.
\end{abstract}

\section{Introduction}

Prefabricated building is a great change of building construction method. After the Second World War, large-scale and quickly rapid in order to meet the needs of residential construction, and then improve the quality of comprehensive construction. In order to make the developed countries widely use the construction method of composite building. At present, most of China's construction sites are still sorted out. The proportion of buildings in new buildings is less than $5 \%$, which is much lower than the international advanced level. The establishment and implementation of the five development concepts of modular building development, innovation, adjustment, green, openness and sharing; and promote the innovation of methods according to the conditions of use, economy and safety. Elegant and beautiful environment is also an important means to stabilize growth, promote reform and adjust structure. This is the construction of ecological civilization, and it is very important to comprehensively promote the new urbanization, especially to promote the realization of Chinese dream.

\section{An overview of prefabricated buildings}

\subsection{The concept of prefabricated building}

The definition of prefabricated building: Modern industrial method and modern industrial organization, through the residential industrial production of each stage of the technical means and system integration, combined with production factors, to achieve the standardization of building ${ }^{[1]}$.

Traditional buildings must be moved to the site to supply steel, concrete and other building materials. Pillars, wainscots, balconies and steps, namely "building blocks", and can be produced in advance in the factory. Can be simply combined and set up after being transported on site.

\subsection{Characteristics of prefabricated buildings}

(1) The construction can realize the industrialization of factory parts, directly install the construction site, which are directly convenient, fast, and using a very short project time. Meanwhile, which can speed up the project speed. A 15-story building can be built in a week.

(2) The high mechanization of parts can greatly reduce the number of on-site construction personnel. Reduce the waste of materials to a certain extent; and greatly improve the efficiency of materials. Does not disturb the people's healthy and bid farewell to the "gray" construction site.

(3) For example: the floor thickness of traditional building is about $100 \mathrm{~mm}$, the floor thickness of prefabricated building is $60 \mathrm{~mm}$. The composite plate of prefabricated building is $80 \mathrm{~mm}$. The total thickness of composite slab is $140 \mathrm{~mm}$. The increase of material consumption leads to the increase of cost. However, the standardization of design, the improvement of management information and production efficiency will reduce the cost of corresponding components of the digital management of complete equipment. The cost

* Corresponding author: 635702249@qq.com 
performance of the whole composite building is getting higher and higher.

(4) The prefabricated structure produced in the factory can improve the wall cracks, leakage and other general quality problems to the greatest extent; and improve the overall safety level, fire performance and durability of the residence ${ }^{[2]}$. The steel bullet of prefabricated PC components even has fixed connection and fixed parts, thus ensuring the integrity of the residence. Compared with the assembled large plate structure, the quality has been greatly improved.

\section{Problems in site construction of assembly building projects}

\subsection{Influence of large assembly parts on vertical conveying machine}

The biggest difference between the construction of preconstruction project and the traditional construction method is increased a lot of sling work. Which requires some equipment to adjust the transportation of these assembly parts. For example, in residential projects, you can often see assembled large components composed of wife and ladder parts, which weigh 4 to 5 tons and 6 to 7 tons respectively. The reasonable way to form largescale equipment is that the smooth implementation of the whole project, cost management, and the improvement of construction efficiency are very important. The selection and configuration of longitudinal transportation equipment is an important difficulty in the construction and management of composite buildings. Building.

\subsection{Number of projects}

The According to the types of components and the traditional on-site processing method of construction management. The production factors can be simply divided into "reinforcement workers", "Template's workers" and "concrete workers" to complete the whole project. As the number of assembly parts increases, the number of assembly parts increases, and the number of managed assembly parts also increases. Components are converted into tens of thousands of components, tens of thousands of assembly components may be classified into dozens of categories, so it is very difficult to manage.

\subsection{Storage place and transportation organization of land using}

In the traditional construction process, the largest means of transport is the concrete transport vehicles, including the fire steel transport vehicles, entering the construction site. However, after the construction of the prefabricated construction project, the storage place in the land is changed by the steel plant and wood. When some projects must accumulate a large number of assembly parts on site due to the actual conditions, the problem is particularly serious. How to set the unloading location?
How to set the bicycle lane, limit the turning radius of the road, and the gradient of the transportation road? This is one of the priorities of adjusting the whole website.

\subsection{Tower group construction, project coordination and safety management}

In the whole machine assembly and crane construction process, you need a large crane to complete the construction of the crane. In terms of safety, cranes in the air often lift a few tons of light weight, light weight and safe prefabricated buildings in the process of preheating construction, which is very different from traditional construction..

\subsection{Improve the management of parts production, installation and finished product protection}

If the component factory should be considered in the production, then how to protect the finished products in the installation process and storage process must be paid attention to on site. Compared with the hoisting of steel structural members, the hoisting of prefabricated concrete members needs to pay special attention to two aspects: first one is that prefabricated concrete members are more vulnerable than steel structural members; the second one is that concrete members are more vulnerable than steel structural members. The installation accuracy of fabricated components is not lower than that of steel structure. Therefore, the finished product protection of prefabricated concrete components is reflected in the process of lifting and storage, collision prevention, and anti-crack measures in storage measures. Those are the key points of project planning. If these links are wrong, the implementation of the whole project will be affected.

\section{Application of BIM and RFID technology in prefabricated building projects}

\subsection{The implementation principle of BIM and RFID technology}

\subsubsection{The implementation principle of BIM technology}

BIM Technology is also called building information model. Based on the important information data of project links, the application of BIM in construction projects establishes the corresponding building model, and then uses digital information policy technology to collect and select all types of information related to construction. The development of network technology has the following three characteristics ${ }^{[3]}$.

(1) Regard those as the basic information data elements and important data sets in the project to form 
the database. The data must be very uniform and fully shared.

Basic information, graphic information and various information of the building parts. BIM technology collects various forms of information to form relatively rich unit data information. Finally, the information models are transformed between each other. Dynamic information model transformation can effectively update relevant data information and automatically generate corresponding documents and photos.

\subsubsection{The implementation principle of RFID technology}

RFID wireless frequency technology is also closely related to people's wireless communication technology. Therefore, it is necessary to accurately identify the wireless frequency technology system and target recognition, mechanical contact and radio waves without a variety of important factors. Information content: recycling, leading software, middleware, and information related components, including: the characteristics of RFID technology are mainly divided into three aspects: (1) The realization of non-contact information collection, can achieve accurate, noninterference block in the remote communication, has a very strong penetrability. (2) It can accept the information contained in multiple electronic tags at the same time, with high efficiency of information acquisition. (3) RFID technology has great resistance to pollution, but it also has great durability.

\subsection{Application of BIM technology in the construction management of assembly building}

BIM technology mainly includes three parts: practical field management, 5D dynamic state control, and visual description.

(1) Based on the construction site management BIM, the construction site management is mainly completed by completely imitating the construction process of machine tools. Mimic the site condition of the main material to minimize two treatments.

(2) Implement 5D dynamic construction control based on the 5D dynamic state of BIM, create 5D building information model based on time and check the existence of materials to execute. In the process of reasonable and practical construction, the problem lies in forming the manufacturing method of the project, the allocation of resources, the adjustment of resources, the best method, the best purpose, and the best system structure. In the various operations before construction, it is important to use new techniques, new processes, and complex terminology to eliminate ambiguities.

(3) Disclosure of visualization technology. In each work process before construction, the vision is clear, that is the virtual display of the construction technology using BIM technology. Especially the full-size threedimensional display of new technology, new process and complex nodes; which effectively reduces the wrong understanding of human subjective factors. Make information disclosure more intuitive, easier to understand, and make communication between different departments more effective.

\subsection{Application of RFID Technology in Construction Management of prefabricated Building}

(1) Part manufacturing stage. In the part manufacturing stage, the manufacturer of the manufacturing plant writes all the information of the parts or parts (the size of the column to be manufactured, maintenance information, etc.) in the following ways. Read and write device. According to the user's requirements and the current coding method, the component is coded according to the coding rules of the project contract list. All information about the component will be embedded in the component system, and also, the operator will read and reference it in the next phase.

(2) Transportation of parts and components. In the transportation stage of parts or components, in order to effectively reduce the transportation cost. The transportation status of transportation means will be collected at any time; and also in order to find the shortest path and the shortest time line. The RFID chip is mainly embedded in the transportation device. Speed up the project's operation.

(3) Accept and manage components. The card reader in the system shall immediately inform the relevant personnel of the decision to accept the entrance inspection and on-site acceptance after receiving the entry information of the transport vehicle. After passing the inspection, the arrival information of the components and accessories is transmitted to the designated place for stacking $^{[4]}$, and the RFID chip is input to check the use of the future arrival information and accessories.

(4) The rising stage of spare parts. The workers on the ground and the operators of the construction machinery have the reading devices and the display screen respectively. While the workers on the ground read the relevant information of the parts and display it on the screen in the end. The machine operator can lift the equipment according to the information on the display to save time and energy. In addition, the use of RFID technology can achieve accurate positioning in a narrow range, which can quickly locate and transport vehicles and improve work efficiency.

\subsection{Integrated application of BIM and RFID in construction process management of construction projects}

In modern information management system, BIM and RFID include building management and material monitoring system. The combination of BIM and RFID technology establishes the process management system architecture of modern information technology platform construction based on BIM and RFID. In other words, in order to obtain the location information and progress information of the components in the software application model. The location attribute and progress 
attribute are added to the database of BIM model. The specific uses have been discussed below.

The database based on configuration and delivery BIM model can transmit the collected RFID information to the basic database immediately. Through the defined location attribute and progress attribute, and make it consistent with the model. In addition, RFID feedback information can accurately predict whether components can enter the website according to the plan, then compare and analyze the actual process and expected progress. If there is disengagement, then the schedule and construction process must be adjusted in time to avoid the accumulation of idle labor, spare parts, land, and capital.

Input and field management of components. After the component is accepted, the component information read by the RFID reader is transmitted to the database. The correctness of the information is compared with the location attribute and progress attribute of the BIM model. At the same time, you can use the location attributes of components defined in the BIM model to explicitly display the location of each component. In the storage of parts and materials, in order to avoid secondary processing which need to record one by one.

The rising stage of components. If only there is one mode, relying on manual input of publicity information is not only easy to make mistakes, but also unable to achieve timely transmission of information. If there is only RFID model, the component information can only be displayed in the database. Abstract imagination can be realized through two-dimensional pictures, and the results may vary according to each director. BIM and RFID can promote the instant dissemination of information, and provide binary comparison of progress and quantification from a specific three-dimensional perspective.

\section{Conclusion}

The decreasing of real estate development will affect the downstream parts enterprises, and the development of many parts industry is also very slow. The development of assembly building brings new opportunities to the development of parts enterprises. Preheating materials, thermal insulation materials, doors and windows, pipe joints and pipes, wall tiles, and many other components are inseparable. The only way to realize the prefabricated buildings and the industrialization of buildings is the industrialization of parts industry. Different from traditional buildings, prefabricated buildings have new requirements for sealing and heat insulation. For example, the traditional external wall insulation process is unstable, short service life, cracks, and desquamate on the wall; and also the poor heat cutoff, wall permeability, decorative and so on. The life of buildings; such as walls and the walls of buildings; all need to have the same life span. While strengthening the requirements of parts for pre-hub parts, high standards will indirectly eliminate the rear production capacity; improve the market competitiveness of parts enterprises; and bring new development opportunities for the industry in development difficulties. Prefabricated building will become the future trend of real estate development, which is a necessary condition for green building development and building industrialization development. This active development will be brought new business opportunities for the cooperation and development of the whole industry chain ${ }^{[5]}$. In summary, at this stage, the development process of my country's new urbanization project construction is gradually deepening and accelerating. In fact, in the process of rapid development and changes in the construction and economic operation of my country's key cities, many key city construction industries in the country have gradually obtained rapid and healthy development and continuous progress. The construction industry has had a very important international socio-economic impact in the rapid economic and social development of developed countries for a long time, and its development has also occupied an important international industry leading position and international application value. Although the new construction project of prefabricated building structure is at the initial stage of the preliminary development of construction technology, there are still certain structural problems of various forms in various structural forms used for construction of construction projects. In this new process of transformation and development, it is more necessary to continuously improve and continuously optimize the construction of the safety and quality supervision and management system of construction projects in my country. At the same time, it is necessary to carry out a key integration, combing and re-integration of the industry technical standard resource allocation system of the current domestic construction engineering decorative building materials market, and continue to improve the national technical standards of relevant industries. In this way, in line with the actual needs of the continuous development of the actual industry demand in my country's market and the actual needs of the main basic premise of good market demand, the production and operation quality management service industry of the pre-construction project of large-scale high-rise construction projects in my country will continue to develop towards a good The direction of international market demand continues to develop and operate in a healthy manner.

\section{References}

1. Wang Yue, Sun Zhengtao. Jushe, 3, 102(2018)

2. Liu Juan.Sichuan cement, 9, 206(2018)

3. Liu Yang. China new technology and new products, 18, 127(2016)

4. Liu Hongsheng. construction engineering technology and design, 3, 102(2018)

5. Zhao Tianxiang. Commodity and quality,4, 26(2017) 